\title{
Melatonergic Drugs for Therapeutic Use in Insomnia and Sleep Disturbances of Mood Disorders
}

\author{
Venkatramanujam Srinivasan ${ }^{*}, 1$, Rahimah Zakaria ${ }^{2}$, Zahiruddin Othaman $^{3}$, Amnon Brzezinski $^{4}$, \\ Atul Prasad ${ }^{5}$ and Gregory M. Brown ${ }^{6,7}$
}

\author{
${ }^{I}$ Sri Sathya Sai Medical Educational and Research Foundation Prasanthi Nilayam, 40-Kovai Thirunagar, Coimbatore- \\ 641014 Tamilnadu, India \\ ${ }^{2}$ Department of Physiology, School of Medical Sciences, Universiti Sains Malaysia, Health Campus, 16150 Kubang \\ Kerian Kelantan, Malaysia \\ ${ }^{3}$ Department of Psychiatry, School of Medical Sciences, Universiti Sains Malaysia, Health Campus, 16150 Kubang \\ Kerian Kelantan, Malaysia \\ ${ }^{4}$ Department of Obstetrics and Gynecology, The Hebrew University Hadassah Medical Center, Jerusalem, 91120, Israel \\ ${ }^{5}$ Department of Neurosciences, Fortis Hospital, Vasant Kunj, New Delhi 11070, India \\ ${ }^{6}$ Department of Psychiatry, Faculty of Medicine, University of Toronto, Toronto, Canada \\ ${ }^{7}$ Centre for Addiction and Mental Health, 250 College Street, Toronto, ON, M5T 1R8, Canada
}

\begin{abstract}
Insomnia is common among elderly people and nearly 30 to $40 \%$ of the adult population also suffer from insomnia. Pharmacological treatment of insomnia include the use of benzodiazepine and non-benzodiazepine drugs like zolpidem, zaleplon,Zopiclone. Although these drugs improve sleep ,their usage is also associated with number of adverse effects, Melatonin ,the hormone secreted by the pineal gland of all animals and human beings has been used for treatment of insomnias,since the timing of its secretion in humans as well as in most of the animals coincides with the increase of nocturnal sleep propensity.Because of its short half life,melatonin slow release preparations were introduced for treatment of insomnia. Recently ramelteon ,a selective MT1,MT2 receptor agonist with greater efficacy of action in treating insomnia has been used clinically and has been found effective in improving sleep quality ,sleep efficacy and also in reducing the sleep onset time when compared to melatonin or slow melatonin preparations. The mechanism of action of ramelteon in improving sleep is discussed in the paper. Another melatonergic drug agomelatine besides acting on MT1/MT2 receptors also displays 5-HT2c antagonism and this drug has been found effective as a novel antidepressant for treating major depressive disorders.Agomelatine besides causing remission of depressive symptoms also improves sleep quality and efficiency. Other antidepressants depressants that are in clinical use today do not improve sleep. There are other melatonergic drugs like tasimelteon,6-chloromelatonin.But ramelteon and agomelatine deserve special attention for treatment of insomnia and sleep disturbances associated with depressive disorders and have promising role for treatment of sleep disorders.
\end{abstract}

Keywords: Ramelteon, sleep, agomelatine, depression, insomnia, melatonin.

\section{INTRODUCTION}

Melatonin (N-acetyl-5-methoxytryptamine; MT), first identified by Lerner et al. [1], is the major neurohormone secreted from the pineal gland mainly during dark hours of night and is released in higher concentrations into the cerebrospinal fluid [2]. The circadian pattern of pineal melatonin secretion is regulated by the suprachiasmatic nucleus $(\mathrm{SCN})$ of the hypothalamus. A major portion of the SCN is projected to the supraventricular zone of the hypothalamus from where fibres proceed to terminate in the brain areas involved in sleep-wake regulation [3]. Sleep regulation involves interaction of two separate mechanisms, namely an endogenous biological-clock that drives the

*Address correspondence to this author at the Sri Sathya Sai Medical Educational and Research Foundation, Prasanthi NIlayam, 40-Kovai Thirunagar, Coimbatore-641014, Tamilnadu, India; Tel: 0091-9790360432; E-mail: sainivasan@yahoo.com circadian-rhythm of sleep-wake cycle (process-C) and a homeostatic process (process-S) that influences sleeppropensity, that is determined by the duration of previous sleep episodes [4]. These two processes interact continuously and determine the consolidated bout of sleep at night and consolidated bout of wakefulness during daytime. Melatonin has been suggested to be involved in sleep regulation, since its nocturnal rise leads to "opening of the sleep gate" and augmentation of sleep propensity [5].

Several studies have shown the importance of melatonin both for the initiation and maintenance of sleep [6]. In all diurnal animals and human beings, the onset of melatonin secretion coincides with the timing of increase in nocturnal sleep propensity [5]. As melatonin exhibits both hypnotic and chronobiotic properties, it has been used for the treatment of age-related insomnia as well as other primary and secondary insomnia states $[7,8]$. 
Melatonin has also been used successfully for treatment of sleep problems related to perturbations of the circadian time keeping system like those caused by jet-lag, shift-work disorder or delayed sleep phase syndrome, and in children with chronic sleep-onset insomnia [7, 9-11]. The high density of $\mathrm{MT}_{1}$ and $\mathrm{MT}_{2}$ melatonin receptor subtypes in the hypothalamic SCN [12,13] suggests that melatonin affects sleep and the sleep-wakefulness cycle by acting on these receptors.

The efficacy of melatonin in promoting and maintaining sleep has been demonstrated in a number of clinical studies undertaken both in children with chronic onset insomnia as well in adult and elderly patients with chronic insomnia; however, because of its short half life, its sustained effect in improving sleep quality could not be found uniformly in all clinical studies undertaken so far.

Hence prolonged release preparations of melatonin and melatonin agonists with a longer duration of action on sleep regulatory mechanisms have been developed. These include circadin, beta methyl 6-chlormelatonin, tasimelteon, ramelteon, agomelatine [14].

\section{INSOMNIA}

Insomnia is a sleep disorder characterized by poor quality of sleep with symptoms like difficulty in falling asleep, frequent awakenings during night time, early morning awakenings, etc. Such symptoms resultin fatigue, decreased memory, and impaired performance, all of which havea negative impact on health and quality of life.

Insomnia is most common among elderly people and is a major cause of physical and mental health impairment [15, 16]. Nearly 30 to $40 \%$ of the adult population suffers from mild to severe insomnia [17]. The sequelae of insomnia include fatigue, reduced alertness, irritability and impaired concentration; all these symptoms have major negative impact on the quality of life [18-20]. In addition, due to its broad psychological and physiological impacts, insomnia has social consequences such as increased risk of accidents and reduced productivity [21]. Treatment of insomnia includes life style modifications like relaxation and cognitive therapies, behavioral techniques like sleep hygiene [22] and pharmacologic interventions that employ sedative-hypnotics of both benzodiazepine and non-benzodiazepe drugs.

The non-benzodiazepine drugs like zolpidem, zaleplon, zopiclone that are used, although effective in reducing sleep latency, exhibit only moderate efficacy in increasing sleep efficiency [23]. An ideal hypnotic drug is expected to decrease sleep latency as well to increase sleep efficiency and total sleep time.

\section{MELATONIN AND SLEEP}

The role of melatonin in the control of sleep has been investigated in both diurnal and nocturnal species. Local injection of pharmacological amounts of melatonin (1 to 50 $\mu \mathrm{g})$ in the medial preoptic area of the rat hypothalamus during daytime increased total sleep time (TST) in a dosedependent manner mainly by increasing non-rapid eye movement (NREM) sleep [24]. Melatonin has been shown to induce sleep by altering the functions of the $\mathrm{GABA}_{\mathrm{A}^{-}}$ benzodiazepine receptor complex $[25,26]$. In diurnal species, suppression of electrical activity in the SCN is suggested as the possible mechanism by which melatonin regulates sleep [27]. This effect is absent in $\mathrm{MT}_{1}$ knockout mice showing thereby the importance $\mathrm{MT}_{1}$ receptors in melatonin's acute inhibitory effects on SCN electrical activity [28]. The $\mathrm{MT}_{1}$ and $\mathrm{MT}_{2}$ melatonin receptor subtypes are complementary in their actions and to some extent mutually substitute for each other [13]. The suppression of neuronal activity by melatonin is one of the possible mechanisms by which this hormone contributes to the regulation of sleep [29].

As melatonin deficiency is suggested as a cause rather than a marker for insomnia in the elderly, melatonin replacement therapy has been advocated for treating insomnia in old age. Because melatonin is a natural (endogenous) hypnotic, it is suitable for long term use in elderly people due to its low toxicity and limited side effect profile. Indeed melatonin replacement therapy has been found beneficial in treating elderly insomniacs by significantly improving TST and sleep quality, and by reducing sleep onset latency (SOL) [8, 30-36].

Reduced endogenous melatonin production seems to be a prerequisite for effective exogenous melatonin treatment of sleep disorders in the elderly [8]. A meta-analysis on the effects of melatonin in sleep disturbances at all age groups (including young adults with presumably normal melatonin levels) failed to document significant and clinically meaningful effects of exogenous melatonin on sleep quality, efficiency and latency [37]. However another meta-analysis involving 17 controlled studies has shown that melatonin was effective in increasing sleep efficiency (SE) and reducing SOL in elderly subjects [38].

The relationship between sleep disturbances and low nocturnal melatonin production was investigated in a large population of insomniacs aged 55 years or more [8]. Elderly insomniacs with sleep problems excreted $9.0 \pm 8.3 \mu \mathrm{g}$ of 6 sulfatoxymelatonin (urinary melatonin metabolite) per night, whereas age matched healthy controls excreted $18.1 \pm 12.7$ $\mu \mathrm{g}$ of 6-sulfatoxymelatonin per night, and younger subjects excreted $24.2 \pm 11.9 \mu \mathrm{g}$ of 6 -sulfatoxymelatonin per night. It was also observed that half of the elderly insomniacs excreted less than $8.0 \mu \mathrm{g}$ of 6-sulfatoxymelatonin per night. Within this latter subpopulation of 372 subjects, 112 had urinary 6-sulfatoxymelatonin values lower than $3.5 \mu \mathrm{g}$ per night [8].

Studies carried out using 0.3-1 mg doses of melatonin, that produces physiological melatonin levels in the circulation, have shown that melatonin reduced SL and increased SE when administered to healthy human subjects during the evening [30, 33, 34]. Brain imaging studies in awake subjects have revealed that melatonin modulates the brain electrical activity pattern to one resembling that of actual sleep [39]. Use of melatonin for treatment of children with sleep problems also have been reported in a number of clinical studies. In a randomized double- blind placebo controlled trial conducted by the Dutch Sleep Center involving 62 children of 6-12 years suffering for more than one year from chronic idiopathic sleep onset insomnia, administration of melatonin ( $5 \mathrm{mg} /$ day) for 4 weeks advanced sleep onset time significantly (by 57 minutes) and 
decreased sleep latency [40]. Similarly, use of melatonin (5 $\mathrm{mg}$ /day) in 105 medication free children aged 6-12 years diagnosed with ADHD (Attention Deficit Hyperactivity Disorder) significantly improved total sleep time [41]. The noteworthy feature emerging from these studies is that melatonin treatment in children can be sustained over a long period of time without any substantial deviation in puberty development, mental health scores, or sleep quality of the general Dutch population [42].

The general efficacy of melatonin as a sleep promoting substance has been subject of debate [43]. A possible explanation for this is that administered melatonin doses are too low as suggested by the relative potencies of the recently developed melatonin analogues. Given that the reported lack of efficacy of melatonin could be related to the extremely shorthalf life of the fast release melatonin preparations, the development of slow release formulations has occurred [44]. Circadin $^{\circledR}$, a $2 \mathrm{mg}$ controlled-release preparation of melatonin, developed by Neurim (Tel Aviv, Israel) was approved by the European Medicines Agency (EMEA) as a monotherapy for primary insomnia in elderly subjects. Circadin ${ }^{\circledR}$ was shown to improve the quality of sleep and morning alertness, to reduce $\mathrm{SO}, \mathrm{L}$ and to improve the quality of life in middle-aged and elderly insomniacs [45-47].

\section{Ramelteon}

Ramelteon (Rozerem ${ }^{\circledR}$, Takeda Pharmaceuticals, Japan) is a melatonergic hypnotic analogue that has been demonstrated in clinical trials to be effective and safe. It is a tricyclic synthetic analogue of melatonin with the chemical name $(S)-N$-[2-(1, 6, 7, 8-tetrahydro- $2 H$-indeno[5, 4- $b]$ furan8-yl)-ethyl]propionamide (Fig. 1). In 2005, Ramelteon was approved by the Food and Drug Administration (FDA) for treatment of insomnia. It is a selective agonist for $\mathrm{MT}_{1} / \mathrm{MT}_{2}$ receptors without significant affinity for other receptor systems [48, 49]. In vitro binding studies have shown that ramelteon affinity for $\mathrm{MT}_{1}$ and $\mathrm{MT}_{2}$ receptors is 3-16 times higher than that of melatonin. The selectivity of ramelteon for $\mathrm{MT}_{1}$ has been found to be greater than that of $\mathrm{MT}_{2}$ receptors. The selectivity of $\mathrm{MT}_{1}$ receptors by ramelteon suggests that it targets sleep onset more specifically than melatonin itself [50].

\section{Melatonin Receptors in the SCN}

An understanding of the existence of melatonin receptors in the SCN of the hypothalamus and their mechanism of

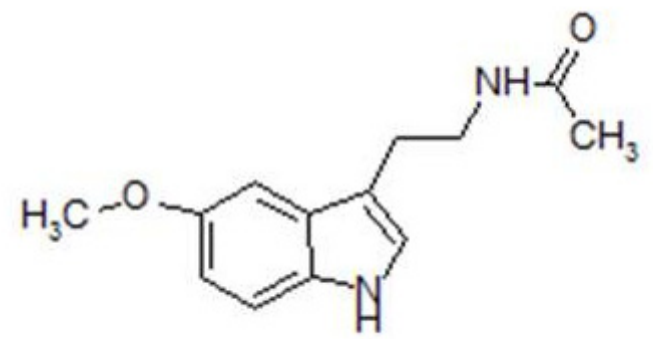

Melatonin action is essential for elucidating the actions of exogenous melatonin in sleep regulation. It was reported that administration of exogenous melatonin $(30-300 \mathrm{pM}$ or $7-70$ $\mathrm{pg} / \mathrm{mL}$ ) decreased the number of $\mathrm{MT}_{2}$ receptors in the $\mathrm{SCN}$ [51]. The decrease in $\mathrm{MT}_{2}$ melatonin receptor numbers induced by melatonin was found to be reversible with full recovery after $8 \mathrm{hr}$. However no such desensitization of $\mathrm{MT}_{1}$ receptors has been reported by the same authors [52]. Desensitization of receptors by agonists is a normal process in G-protein coupled receptors and is a point to be considered while using melatonin for long term in supra physiological concentrations. However there is no clinical evidence for desensitization of melatonin receptors upon use with supraphysiological concentrations of melatonin. This has been demonstrated in experimental studies where use of melatonin receptor agonist S20098 for 14 days did not alter the sensitivity of photically responsive $\mathrm{SCN}$ cells to melatonin in the SCN neither in vivo (intraperitoneal or iontophoretic application of melatonin) nor in the SCN slices in vitro [53]. Expression of $\mathrm{MT}_{1}$ melatonin receptors has been found in the human SCN [54].

\section{Pharmacokinetics of Ramelteon}

Ramelteon is usually administered by the oral route and is absorbed rapidly from the gastrointestinal tract $(84 \%)$ [55]. The half-life of circulating ramelteon is in the range of 1 to $2 \mathrm{hr}$ which is much longer than that of melatonin. The influence of age and gender on the pharmacokinetics and the pharmacodynamics of ramelteon were evaluated in healthy volunteers (young: 18-34 yr, elderly: 63-79 yr) after administration of a single dose of ramelteon. The clearance of ramelteon was significantly reduced in elderly compared to young individuals. No significant gender effect was observed [55].

Ramelteon is metabolized mainly in the liver via oxidation of hydroxyl and carbonyl groups, and then conjugated with glucuronide [56]. Cytochrome P4501A2 is the major hepatic enzyme involved in ramelteon metabolism. Four principal metabolites of ramelteon have been identified, M-I to M-IV [56]. Among these, M-II has been found to occur in a much higher concentrations with systemic levels 20-100 folds greater than ramelteon itself. Although the activity of M-II is 30-fold lower than that of ramelteon, its exposure exceeds that of ramelteon by a factor of 30 . Hence it is suggested that M-II may contribute significantly to the net clinical effect of ramelteon.

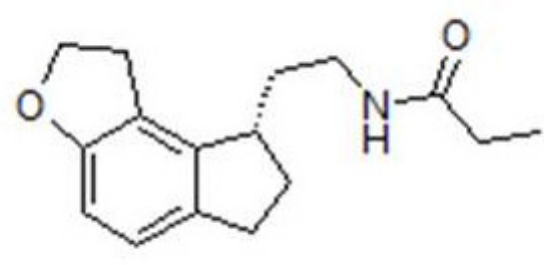

Ramelteon

Fig. (1). Chemical structures of melatonin and ramelteon. 


\section{Mechanism of Ramelteon Sedative-Hypnotic Action}

Although $\mathrm{MT}_{1}$ and $\mathrm{MT}_{2}$ receptors are widely distributed in the brain outside of the SCN [57-61], the high density of melatonin receptors in the SCN and their relationship to the circadian pacemaker function and in particular to sleep-wake cycle are highly suggestive of the SCN melatonin receptor role in sleep regulation. The selectivity of Ramelteon for $\mathrm{MT}_{1}$ and $\mathrm{MT}_{2}$ melatonin receptors indicates that its probable sleep related site of action is in the $\mathrm{SCN}$.

A "sleep-switch" model to describe the regulation of sleep-wakefulness was originally proposed by Saper and his colleagues [3, 62]. It consists of "flip-flop" reciprocal inhibitions among sleep-associated activities in the ventrolateral preoptic nucleus and wakefulness associated activities in the locus coeruleus, dorsal raphe and tuberomammillary nuclei. The SCN has an active role both in promoting wakefulness as well as in promoting sleep and this depends upon a complex neuronal network and a number of neurotransmitters released from networks of GABA, glutamate, arginine vasopressin, somatostatin, etc. $[63,64]$.
Ramelteon may accelerate sleep onset by influencing the hypothalamic sleep switch downstream from the $\mathrm{SCN}$ in the same way as that of melatonin $[65,66]$. Ramelteon promotes sleep onset through inhibition of SCN electrical activity and the consequent inhibition of circadian wake signal thereby activating the specific sleep-circuit pathway. The interrelations of melatonin and $\mathrm{SCN}$ in the control of sleep are shown in Fig. (2).

\section{Clinical Studies on Ramelteon}

The first study on the effects of ramelteon on sleep was conducted by Roth and his co-workers in 2005 [67]. In that study involving 117 patients (16 to $64 \mathrm{yr}$ ) drawn from 13 centers in Europe, the efficacy, safety and dose response of ramelteon were examined. Each patient was randomized to a dose sequence of 4, 8, 16 or $32 \mathrm{mg}$ of ramelteon. All doses of ramelteon produced a statistically significant reduction in latency to persistent sleep (LPS) and increased TST as shown by polysomnographic (PSG) [67].

In a follow-up study, the same group of investigators administered ramelteon for a period of five weeks to 829 patients (>65 years) [68]. In this double blind study

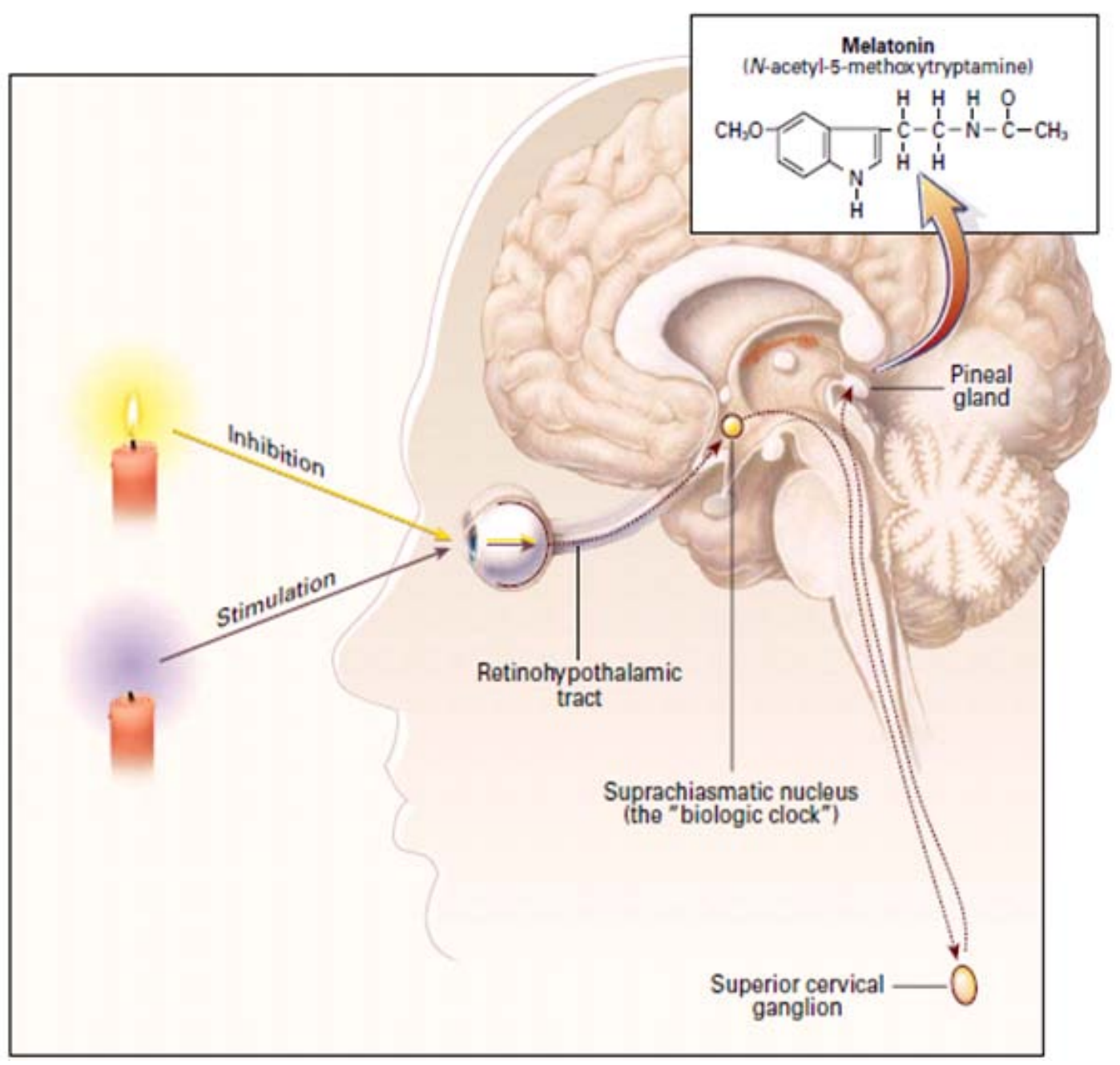

Fig. (2). The interrelations between melatonin, suprachiasmatic nucleus (SCN) in the control of sleep and circadian rhythms. Reproduced with kind permission of The New England Journal of Medicine; Brzezinski, A. Melatonin in humans, New Eng J Med, 1997, 336, 186-195. 
ramelteon, doses of 4 or8 $\mathrm{mg} /$ day brought out a significant reduction in SOL (16\% to 35\%). TST was increased by both doses of ramelteon. In another randomized, multicenter double-blind, placebo-controlled crossover study including 107 patients followed by PSG, ramelteon was studied in doses of 4-32 mg/day [69]. The treatment decreased LPS and increased TST significantly.

A short term evaluation of the efficacy of ramelteon was performed in 100 elderly subjects by administering 4 and 8 $\mathrm{mg}$ doses in a two night/three day period crossover design [70]. LPS was decreased, and TST and SE were augmented as compared to placebo. Likewise, the efficacy of ramelteon in reducing SOL and in increasing TST and SE was evaluated in 371 patients given 8 or $16 \mathrm{mg}$ of ramelteon for 5 weeks in a double-blind, placebo-controlled study [71]. The results confirmed the effect of ramelteon to reduce SOL and to increase SE and TST [71].

The hypnotic action of ramelteon $(8 \mathrm{mg})$ was so rapid that it caused significant reductions in SOL within a week (63\% for ramelteon vs $39.7 \%$ for placebo, $\mathrm{p}<0.001)$ [72]. This reduction in LPS was sustained throughout the 5 weeks of study (63 and $65.9 \%$ ramelteon $v s \quad 41.2$ and $48.9 \%$ placebo at the end of the $3^{\text {rd }}$ and $5^{\text {th }}$ week, respectively) [65]. Ramelteon $(8 \mathrm{mg}$ ) reduced LPS and increased TST in 6week long study involving healthy women [73].

In another 6 month study performed in 451 adults suffering from chronic insomnia drawn from different centers across the globe (mainly USA, Europe, Russia and Australia), ramelteon consistently reduced LPS when compared to placebo [74]. The baseline LPS decreased from 70.7 to 32.0 minutes at week one (with ramelteon) and this reduction in LPS was maintained at months $1,3,5$ and 6 . No adverse effects such as next morning residual effects, rebound insomnia or withdrawal effects were noted [74].

In a double-blind placebo controlled study involving a large number of Japanese patients with chronic insomnia $(n=1130)$, the efficacy and safety of 4 and $8 \mathrm{mg}$ ramelteon doses were evaluated [75]. No statistically significant differences were found in subjective SOL as compared to the placebo group with $4 \mathrm{mg} /$ day of ramelteon while with 8 $\mathrm{mg} /$ day of ramelteon a significant increase in TST and a decrease in SOL were observed.

The same investigators evaluated the efficacy and safety of ramelteon in 190 Japanese adults with chronic insomnia treated for a period of 24 weeks [76]. TST significantly increased with ramelteon $(8 \mathrm{mg} /$ day) and this effect was maintained for 20 weeks. In this study, ramelteon was well tolerated and it did not cause residual effects, rebound insomnia, withdrawal symptoms or dependence even after 24 weeks of continuous treatment [76].

Therefore, in all clinical studies undertaken so far to evaluate the efficacy and safety of ramelteon in various doses ranging from 4 to $32 \mathrm{mg} /$ day in patients with chronic insomnia, the drug reduced SOL and increased sleep duration $[65,77]$. Besides acting as a sedative-hypnotic drug, ramelteon also exhibited chronobiotic properties. In a study conducted on 75 healthy human subjects, the administration of ramelteon at doses of $1,2,4$ and $8 \mathrm{mg}$ for 6 days caused significant advancement of dim light melatonin offset [78].
Interestingly, data from a recent randomized, placebocontrolled study suggested that ramelteon can also be beneficial for the treatment of ambulatory bipolar I disorder patients with manic symptoms and sleep disturbance [79]. Twenty-one outpatients with bipolar I disorder with mild-tomoderate manic symptoms and sleep disturbance were randomized to receive either ramelteon $(n=10)$ or placebo $(\mathrm{n}=11)$ in an 8 -week, double-blind, fixed-dose $(8 \mathrm{mg} /$ day $)$ study. Ramelteon and placebo had similar rates of reduction in ratings of symptoms of insomnia, mania, and global severity of illness. However, ramelteon was associated with improvement in a global rating of depressive symptoms. It was also well tolerated and associated with no serious adverse events [79].

\section{Ramelteon Effects on Sleep Disturbances of Jet Lag}

Both objective and subjective studies using either actigraphy or polysomnography has shown that poor sleep is one of the characteristic features seen during time zone transitions. Sleep fragmentation, premature awakening, difficulty in initiating sleep constitute the most important features of jet-lag associated sleep disturbances [80]. The effects of transmeridian travel on various sleep parameters such as total sleep time, sleep onset latency and sleep offset was evaluated in a study in which academicians travelled from Japan to USA and Canada back. Significant decreases in total sleep time were noted on the second post-travel day in eastward travel [81]. Melatonin at a $5 \mathrm{mg}$ dose was administered in a double-blind, randomized placebocontrolled study to evaluate its efficacy on sleep parameters where it was found that it increased slow sleep but its effects on sleep parameters did not differ much from that of placebo [82].

Recently the effects of ramelteon on sleep parameters were evaluated in a group of 110 healthy adults with a history of jet lag sleep disturbances who were flown from Hawaii to the east coast of USA (crossing five time zones). Ramelteon was administered in 1, 4 and $8 \mathrm{mg}$ (or placebo), 5 minutes before local bedtime for four nights. Measurements of sleep parameters by using polysomnography revealed that ramelteon $(1 \mathrm{mg})$ reduced the mean latency to persistent sleep (LPS) on nights $2-4(\mathrm{P}=0.030)$ compared to placebo with no evidence of adverse reports [83]. A Table depicting the efficacy of ramelteon in chronic insomnia is presented in Table 1.

\section{Tasimelteon}

Tasimelteon, (1R-trans)-N-[2-(2, 3dihydro-4benzofuranyl) cyclopropyl) methyl]propanamide is also an $\mathrm{MT}_{1} / \mathrm{MT}_{2}$ receptor agonist. In human studies undertaken on 39 healthy subjects, this drug decreased the sleep latency, increased sleep efficiency and also shifted melatonin rhythm, various doses ranging from $10 \mathrm{mg}, 20 \mathrm{mg}, 50 \mathrm{mg}$ and $100 \mathrm{mg}$ were used in this study [84]. However the effectiveness and safety of tasimelteon in insomnia can be ascertained only after undertaking long term studies [85].

\section{6-Chloromelatonin (LY156735)}

Beta-methyl 6-chloromelatonin is another $\mathrm{MT}_{1} / \mathrm{MT}_{2}$ receptor agonist. LY156735 has been shown to induce sleep 
Table 1. Summary of the Clinical Effects of Ramelteon in Patients with Chronic Insomnia

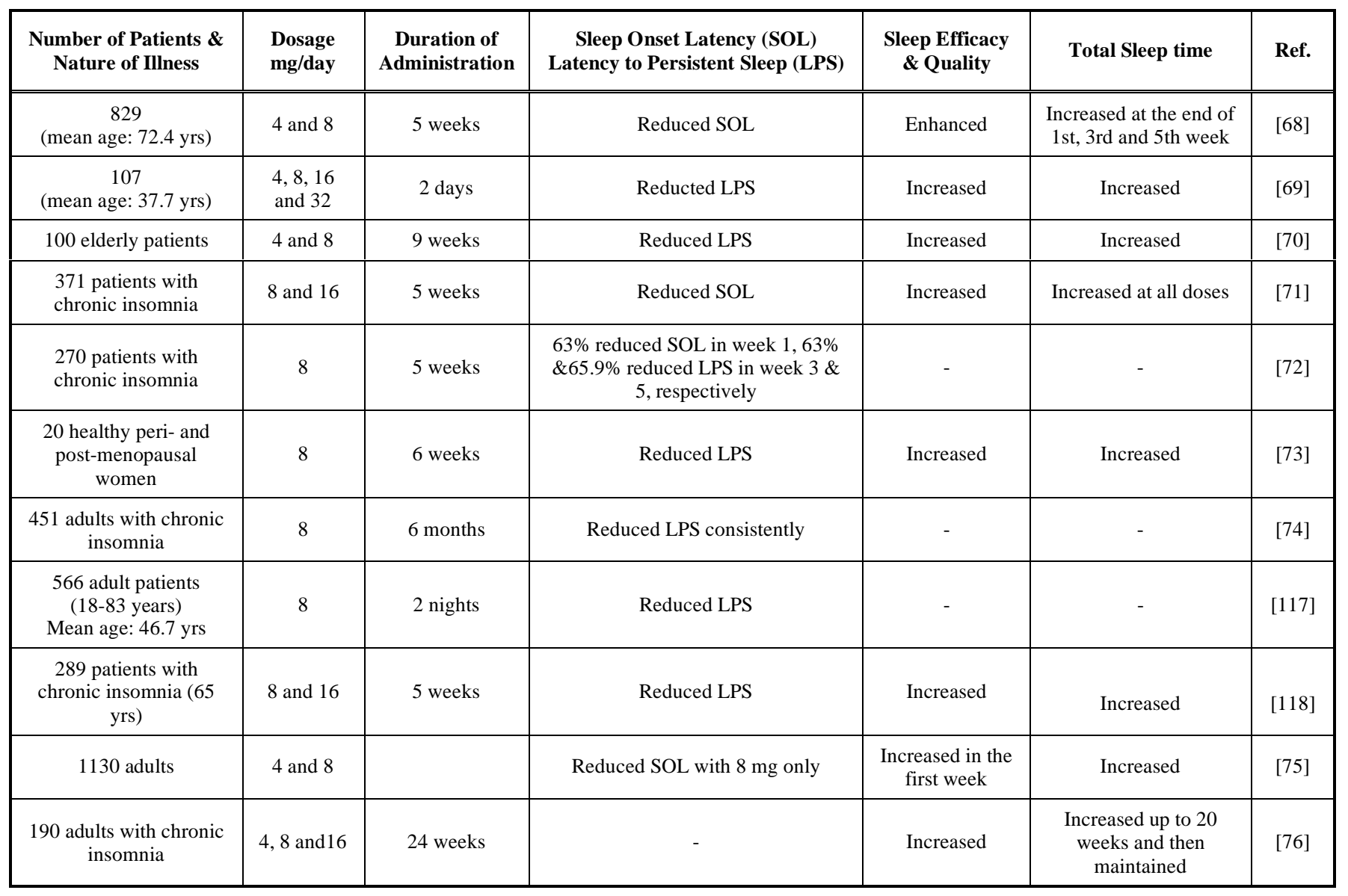

at all doses tested $(20,35,50$ and $100 \mathrm{mg} /$ day) in placebo controlled studies undertaken in healthy volunteers [86]. In a double-blind study on 40 patients with chronic insomnia, 6chloromelatonin (20, 40 and $100 \mathrm{mg}$ ) caused significant improvements both in subjective and objective measures of sleep onset latency at higher doses but caused a trend of improvement at the $20 \mathrm{mg}$ dose [87].

\section{Sleep and Circadian rhythm Disturbances, Depression and the Use of Agomelatine}

Depressive patients experience difficulty in falling asleep, staying asleep and display early morning wakefulness [88]. Disruptions in sleep homeostasis constitute one of the major features of depressive illness. Decreased REM sleep latency with alteration of temporal distribution of sleep is often seen in patients with major depressive disorder [89]. Chronic insomnia is considered both as a prominent feature as well as predictor of depressive illness [90]. Understanding the physiological mechanisms of sleep regulation especially their sequellae and their breakdown can help one to unravel the complexities of the pathophysiology of depressive disorders [90]. Sleep disturbances and changes in sleep form three diagnostic criteria for mood disorders in the Diagnostic and Statistical Manual of Mental Disorders-Fourth Edition (DSM-IV-2000). Profound disturbances in sleep architecture have been reported in about $80 \%$ of depressive patients with major depressive disorders (MDD) or bipolar disorder (BPD) [91]. Insomnia often precedes the appearance of mood changes [92]. In addition to sleep disturbances disruptions in biological rhythms are also strongly associated with mood disorders [93, 94]. Mood disorders such as MDD and BPD have been shown to be prevalent in individuals that have abnormal biological clocks or arrhythmic clocks $[95,96]$. In addition to this, individuals with genetic sleep disorders also manifest symptoms of depression and anxiety [97, 98], These include persons with familial advanced phase sleep syndrome (FASPS), whose circadian rhythms are shifted earlier and, as a result, fall asleep and wake up much earlier than desired, or delayed sleep phase syndrome (DSPS) in which individuals sleep and wake up later.. Circadian rhythms as well as sleep-wake rhythms are regulated by a molecular clock located in the SCN of the hypothalamus that consists of a transcriptional feedback loop that cycles over the course of approximately $24 \mathrm{hr}[99,100]$. Abnormalities in the functioning of the molecular clock underlie the development of mood disorders like MDD and BPD and sleep-wake disorders [101]. Although the central circadian pacemaker is located in the SCN, the circadian genes that make up the molecular clock control the circadian rhythms and regulate mood and sleep-wake cycles in normal individuals. Genetic variations in the circadian genes have been found to associate with sleep disorders and diurnal preference measures include an association between certain variants of Per 2 and CK $1 \delta$ with FASPS; Per3, CLOCK and CK1 1 with DSPS; and Per1, Per2, and Per3, with diurnal preference [102-105]. Analysis of function of these circadian genes suggests a connection between mood regulation and 
normal functioning of the circadian clock [106]. Therapeutic modalities that shift, reset and stabilize the circadian rhythms constitute successful methods of treating sleep-wake and mood disorders. While prescribing antidepressants caution should be exercised. An ideal antidepressant should not only mitigate symptoms of depression, but also should improve the sleep quality and efficiency. Although selective serotonin reuptake inhibitors (SSRIs) constitute the major class of antidepressants that are prescribed, their use in depression exacerbates the insomnia of depressive illness [107].

Agomelatine, a melatonergic agonist developed by Servier Laboratories (France) is a naphthalenic compound chemically designated as [N-[2-(7-methoxynaphthth-1-yl)ethyl] acetamide]. It has high affinity for both $\mathrm{MT}_{1}$ and $\mathrm{MT}_{2}$ melatonergic receptors and also functions as a $5-\mathrm{HT}_{2 \mathrm{c}}$ receptor antagonist. Agomelatine does not exhibit any significant affinity towards muscarinic, histaminergic, adrenergic, GABAergic or dopaminergic receptors and their subtypes [108, 109]. Agomelatine was recently licensed in Europe by the European Medicine agencies for treatment of major depressive disorders. The efficacy and safety of agomelatine has been has been proved in a number of multicenter studies conducted in Europe. The noteworthy point emerging from these clinical studies is that agomelatine has been clinically effective in doses of 25 $50 \mathrm{mg} /$ day even in a severely depressed population. The clinical efficacy of agomelatine in MDD and other mood disorders has been reviewed elsewhere [110, 111]. Unlike other antidepressants that are in clinical use, agomelatine was effective in improving the sleep quality and efficacy of patients with MDD, BPD and seasonal affective disorder (SAD). In a study conducted on 165 patients of major depressive disorders, it was found that agomelatine $(25 \mathrm{mg} /$ day) caused earlier and improvements on the criteria of "getting into sleep" and quality of sleep. These improvements in sleep parameters were evident from first week of treatment onwards and this was not the case in patients treated with the antidepressant venlafaxine [112]. In another study conducted on patients with MDD, agomelatine treatment $(25 \mathrm{mg} / \mathrm{day})$ for 6 weeks, increased the duration of slow wave sleep (SWS) without affecting REM sleep duration. In this study, improvements in sleep quality also started from the first week of treatment $[113,114]$. In a study conducted on the effect of agomelatine on cyclic alternating pattern of sleep (CAPS), agomelatine $(25 \mathrm{mg} /$ day $)$ significantly decreased CAPS time and CAPS cycles and normalized NREM sleep in depressive patients. The changes in NREM sleep variables preceded the improvements in subjective mood suggesting thereby that agomelatine's antidepressant mechanism of action is also attributed through its ability in improving the sleep quality [115]. Antidepressants that are in clinical use today elevate daytime mood by activating central nervous system effects. If these energizing effects are sustained into the night it will result in impairment of sleep quality [116]. Agomelatine has a dual mechanism of actions, of improving sleep quality as well as exerting rapid antidepressant actions. Agomelatine's melatonergic effects of sleep promotion counteract the antihypnotic effects caused by the $5-\mathrm{HT}_{2 \mathrm{c}}$ receptor antagonism.

\section{CONCLUSION}

Melatonin exhibits both hypnotic and chronobiotic properties and thus has been investigated for inducing sleep and treating sleep disorders in children, adults, and elderly people. The results of clinical studies with melatonin on sleep outcomes, however, have not been consistent, probably due to its short-half life and and rapid metabolismed after oral administration of fast release preparations.

The melatonergic agonist, ramelteon $\left(\right.$ Rozerem $\left.^{\circledR}\right)$ has been effective in treating insomnia and sleep-wake rhythm disorders. It has shown promising results in the treatment and management of insomnia. In a number of clinical trials, ramelteon has proved its efficacy as a safe hypnotic drug. This melatonergic drug, acting through $\mathrm{MT}_{1}$ and $\mathrm{MT}_{2}$ melatonergic receptors in brain, particularly the SCN, is effective and promising for promoting sleep quality and efficiency without adverse side effects compared to benzodiazepine and non-benzodiazepine sedative drugs. Other melatonergic drugs like tasimelteon or 6chloromelatonin also increased sleep efficiency and decreased sleep latency. However a larger number of clinical trials is needed to prove the efficacy of these molecules for the treatment of insomnia.

Melatonin-like compounds exert sleep-promoting effects by amplifying day/night differences in alertness and sleep quality and by displaying effective sleep inducing effects, when compared to the efficacy of benzodiazepine or nonbenzodiazepine hypnotic drugs. Because they act in a natural way in promoting sleep and their long-term use has not been associated with side effects such as dependency, next-day hangover, memory impairment, cognitive dysfunction, or psychomotor retardation, melatonergic hypnotic drugs, especially ramelteon have a promising role in the treatment of insomnia. The novel melatonergic antidepressant, agomelatine has been shown to produce relatively rapid remission of depressive symptoms in a number of clinical trials involving a large number of patients selected from many European countries. Unlike the other antidepressants that are in use, agomelatine exhibits a dual mechanism of action of improving both the sleep quality and causing remission of depressive symptoms. Unlike the other antidepressants that are in clinical use, agomelatine improves both night time sleep and day time alertness and thus exerts a novel antidepressant effect.

\section{CONFLICT OF INTEREST}

V. Srinivasan is the Founder Chairman of Sri Sathya Sai Medical Educational and Research Foundation, Kovai Thirunagar, 641014, India. He declared no competing interests that might be perceived to influence the contents of this paper. All other authors of this review paper declare that they have no proprietary, professional or any other type of personal interest of any kind in any product or services and/or company that could be construed or considered as a potential conflict of interest that might have influenced the views expressed in this manuscript.

\section{REFERENCES}

[1] Lerner, A.B.; Case, J.D.; Takahashi, Y.; Lee, T.; Mori, N. Isolation of melatonin a pineal factor that lightens melanocytes. J. Am. Chem. Soc., 1958, 80, 2587.

[2] Tricoire, H.; Moller, H.; Chemineau, P.; Malpaux, B. Origin of cerebrospinal fluid melatonin and possible function in the integration of photoperiod. Reproduction, 2003, 61, 311-321. 
[3] Saper, C.B.; Scammell, T.E.; Lu, J. Hypothalamic regulation of sleep and circadian rhythms. Nature, 2005, 437, 1257-1263.

[4] Borbely, A.A. A two process model of sleep regulation. Hum. Neurobiol., 1982, 1, 195-204.

[5] Lavie, P. Melatonin: role in gating nocturnal rise in sleep propensity. J. Biol. Rhythms, 1997, 12, 657-665.

[6] Cajochen, C.; Jewett, M.E.; Dijk, D.J. Human circadian melatonin rhythm phase delay during a fixed sleep-wake schedule interspersed with nights of sleep deprivation. J. Pineal Res., 2003, $35,149-157$

[7] Zhdanova, I.V.; Wurtman, R.J.; Regan, M.M.; Taylor, J.A.; Shi, J.P.; Leclair, O.U. Melatonin treatment for age-related insomnia. $J$. Clin. Endocrinol. Metab., 2001, 86, 4727-4730.

[8] Leger, D.; Laudon, M.; Zisapel, N. Nocturnal 6-sulfatoxymelatonin excretion in insomnia and its relation to the response to melatonin replacement therapy. Am. J. Med., 2004, 116, 91-95.

[9] Arendt, J.; Skene, D.J.; Middleton, B.; Lockley, S.W.; Deacon, S. Efficacy of melatonin treatment in jet lag, shift work, and blindness. J. Biol. Rhythms, 1997, 12, 604-617.

[10] Pandi-Perumal, S.R.; Trakht, I.; Spence, D.W.; Srinivasan, V.; Dagan, Y.; Cardinali, D.P. The roles of melatonin and light in the pathophysiology and treatment of circadian rhythm sleep disorders. Nat. Clin. Pract. Neurol., 2008, 4, 436-447.

[11] Srinivasan, V.; Singh, J.; Pandi-Perumal, S.R.; Brown, G.M.; Spence, D.W.; Cardinali, D.P. Jet lag, circadian rhythm sleep disturbances, and depression: the role of melatonin and its analogs. Adv. Ther., 2010, 27, 796-813.

[12] Reppert, S.M.; Weaver, D.R.; Ebisawa, T. Cloning and characterization of a mammalian melatonin receptor that mediates reproductive and circadian responses. Neuron, 1994, 13, 11771185 .

[13] Dubocovich, M.L.; Delagrange, P.; Krause, D.N.; Sugden, D.; Cardinali, D.P.; Olcese, J. International Union of Basic and Clinical Pharmacology. LXXV. Nomenclature, classification, and pharmacology of G protein-coupled melatonin receptors. Pharm. Rev., 2010, 62, 343-380.

[14] Turek, F.W.; Gillette, M.U. Melatonin, sleep, and circadian rhythms: rationale for development of specific melatonin agonists. Sleep Med., 2004, 5, 523-532.

[15] Van Someren, E.J. Circadian and sleep disturbances in the elderly. Exp. Gerontol., 2000, 35, 1229-1237.

[16] Most, E.I.; Scheltens, P.; Van Someren, E.J. Prevention of depression and sleep disturbances in elderly with memoryproblems by activation of the biological clock with light-a randomized clinical trial. Trials, 2010, 11, 19.

[17] Summers, M.O.; Crisostomo, M.I.; Stepanski, E.J. Recent developments in the classification, evaluation, and treatment of insomnia. Chest, 2006, 130, 276-286.

[18] Vgontzas, A.N.; Kales, A. Sleep and its disorders. Annu. Rev. Med., 1999, 50, 387-400.

[19] Cricco, M.; Simonsick, E.M.; Foley, D.J. The impact of insomnia on cognitive functioning in older adults. J. Am. Geriatr. Soc., 2001, 49, 1185-1189.

[20] Bastien, C.H. Insomnia: Neurophysiological and neuropsychological approaches. Neuropsychol. Rev., 2011, 21(1), 22-40.

[21] Drake, C.L.; Roehrs, T.; Richardson, G.; Walsh, J.K.; Roth, T. Shift work sleep disorder: prevalence and consequences beyond that of symptomatic day workers. Sleep, 2004, 27, 1453-1462.

[22] Montgomery, P.; Dennis, J. A systematic review of nonpharmacological therapies for sleep problems in later life. Sleep Med. Rev., 2004, 8, 47-62.

[23] Wilson, S.J.; Nutt, D.J.; Alford, C.; Argyropoulos, S.V.; Baldwin, D.S.; Bateson, A.N.; Britton, T.C.; Crowe, C.; Dijk, D.J.; Espie.C.A.; Gringras, P.; Hajak, G.; Idzikowski, C.; Krystal, A.D.; Nash, J.R.; Selsick, H.; Sharpley, A.L.; Wade, A.G. British Association for psychopharmacology consensus statement on evidence-based treatment of insomnia, parasomnias and circadian rhythm disorders. J. Psychopharmcol., 2010, 24, 1577-1601.

[24] Mendelson, W.B. Melatonin microinjection into the medial preoptic area increases sleep in the rat. Life Sci., 2002, 71, 20672070.

[25] Golombek, D.A.; Pevet, P.; Cardinali, D.P. Melatonin effect on behavior: Possible mediation by the central GABAergic system. Neurosci. Biobehav. R., 1996, 20, 403-412.
[26] Cardinali, D.P.; Golombek, D.A. The rhythmic GABAergic system. Neurochem. Res., 1998, 23, 607-614.

[27] Inyushkin, A.N.; Bhumbra, G.S.; Gonzalez, J.A.; Dyball, R.E. Melatonin modulates spike coding in the rat suprachiasmatic nucleus. J. Neuroendocrinol., 2007, 19, 671-681.

[28] Liu, C.; Weaver, D.R.; Jin, X.; Shearman, L.P.; Pieschl, R.L.; Gribkoff, V.K.; Reppert, S.M. Molecular dissection of two distinct actions of melatonin on the suprachiasmatic circadian clock. Neuron, 1997, 19, 91-102.

[29] Jan, J.E.; Reiter, R.J.; Wong, P.K.H.; Bax, M.C.O.; Ribary, U.; Wasdell, M.B. Melatonin has membrane receptor-independent hypnotic action on neurons: an hypothesis. J. Pineal Res., 2011, 50, 233-240.

[30] Dollins, A.B.; Zhdanova, I.V.; Wurtman, R.J.; Lynch, H.J.; Deng, M.H. Effect of inducing nocturnal serum melatonin concentrations in daytime on sleep, mood, body temperature, and performance. Proc. Nat. Acad. Sci. USA, 1994, 91, 1824-1828.

[31] Haimov, I.; Laudon, M.; Zisapel, N.; Souroujon, M.; Nof, D.; Shlitner, A.; Herer, P.; Tzischinsky, O.; Lavie, P. Sleep disorders and melatonin rhythms in elderly people. BMJ, 1994, 309, 167.

[32] Garfinkel, D.; Laudon, M.; Nof, D.; Zisapel, N. Improvement of sleep quality in elderly people by controlled-release melatonin. Lancet, 1995, 346, 541-544.

[33] Zhdanova, I.V.; Wurtman, R.J.; Lynch, H.J.; Ives, J.R.; Dollins, A.B.; Morabito, C.; Matheson, J.K.; Schomer, D.L. Sleep-inducing effects of low doses of melatonin ingested in the evening. Clin. Pharmacol. Ther., 1995, 57, 552-558.

[34] Zhdanova, I.V.; Wurtman, R.J.; Morabito, C.; Piotrovska, V.R.; Lynch, H.J. Effects of low oral doses of melatonin, given 2-4 hours before habitual bedtime, on sleep in normal young humans. Sleep, 1996, 19, 423-431.

[35] Hughes, R.J.; Badia, P. Sleep-promoting and hypothermic effects of daytime melatonin administration in humans. Sleep, 1997, 20, 124-131.

[36] Monti, J.M.; Alvarino, F.; Cardinali, D.; Savio, I.; Pintos, A. Polysomnographic study of the effect of melatonin on sleep in elderly patients with chronic primary insomnia. Arch. Gerontol. Geriat., 1999, 28(2), 85-98.

[37] Buscemi, N.; Vandermeer, B.; Hooton, N.; Pandya, R.; Tjosvold, L.; Hartling, L.; Vohra, S.; Klassen, T.P.; Baker, G. Efficacy and safety of exogenous melatonin for secondary sleep disorders and sleep disorders accompanying sleep restriction: meta-analysis. BMJ, 2006, 332, 385-393.

[38] Brzezinski, A.; Vangel, M.G.; Wurtman, R.J.; Norrie, G.; Zhdanova, I.; Ben-Shushan, A.; Ford, I. Effects of exogenous melatonin on sleep: a meta-analysis. Sleep Med. Rev., 2005, 9, 4150 .

[39] Gorfine, T.; Assaf, Y.; Goshen-Gottstein, Y.; Yeshurun, Y.; Zisapel, N. Sleep-anticipating effects of melatonin in the human brain. Neuroimage, 2006, 31, 410-418.

[40] Smits, M.G.; Vanstel, H.F.; Vander, Heijden, K.B.; Meijer, M.; Coenen, A.M.; Kerkhof, G.A. Melatonin improves health status and sleep in children with idiopathic chronic sleep onset insomnia; a randomized placebo controlled trial. J. Am. Acad. Child Adolesc. Psychiat., 2003, 42, 1286-1293.

[41] Van der Heijden, K.B.; Smits, M.G.; Van Someren, E.J.; Ridderinkhof, K.R.; Gunning, W.B. Effect of melatonin on sleep behavior and cognition in ADHD and chronic sleep onset insomnia. J. Am. Acad. Child Adoles. Psychiatry, 2007, 46, 233-241.

[42] Van Geiglswijk, I.M.; Mol, R.H.; Eqberts, T.C.; Smits, M.G. Evaluation of sleep, puberty, mental health in children with long term melatonin treatment for chronic idiopathic childhood sleep onset insomnia. Psychopharmacology, 2011, 111-120.

[43] Mendelson, W.B. A critical evaluation of the hypnotic efficacy of melatonin. Sleep, 1997, 20, 916-919.

[44] Dalton, E.J.; Rotondi, D.; Levitan, R.D.; Kennedy, S.H.; Brown, G.M. Use of slow-release melatonin in treatment-resistant depression. J. Psychiatr. Neurosci., 2000, 25, 48-52.

[45] Lemoine, P.; Guilleminault, C.; Alvarez, E. Improvement in subjective sleep in major depressive disorder with a novel antidepressant, agomelatine: randomized, double-blind comparison with venlafaxine. J. Clin. Psychiat., 2007, 68, 1723-1732.

[46] Lemoine, P.; Nir, T.; Laudon, M.; Zisapel, N. Prolonged-release melatonin improves sleep quality and morning alertness in insomnia patients aged 55 years and older and has no withdrawal effects. J. Sleep Res., 2007, 16, 372-380. 
[47] Wade, A.G.; Crawford, G.; Ford, I.; McConnachie, A.; Nir, T.; Laudon, M.; Zisapel, N. Prolonged release melatonin in the treatment of primary insomnia: evaluation of the age cut-off for short- and long-term response. Curr. Med. Res. Opin., 2011, 27, 87-98.

[48] Kato, K.; Hirai, K.; Nishiyama, K.; Uchikawa, O.; Fukatsu, K.; Ohkawa, S.; Kawamata, Y.; Hinuma, S.; Miyamoto, M. Neurochemical properties of ramelteon (TAK-375), a selective MT1/MT2 receptor agonist. Neuropharmacology, 2005, 48, 301310.

[49] Miyamoto, M. Pharmacology of ramelteon, a selective MT1/MT2 receptor agonist: a novel therapeutic drug for sleep disorders. CNS Neurosci. Ther., 2009, 15, 32-51.

[50] Cajochen, C. TAK-375 Takeda. Curr. Opin. Investig. D., 2005, 6, 114-121.

[51] Gerdin, M.J.; Masana, M.I.; Rivera-Bermudez, M.A.; Hudson, R.L.; Earnest, D.J.; Gillette, M.U.; Dubocovich, M.L. Melatonin desensitizes endogenous MT2 melatonin receptors in the rat suprachiasmatic nucleus : relevance for defining the periods of sensitivity of the mammalian circadian clock to melatonin. FASEB $J .$, 2004, 18, 1646-1656.

[52] Gerdin, M.J.; Masana, M.J.; Dubocovich, M.L. Melatonin mediated regulation of human MT1 melatonin receptors expressed in mammalian cells. Biochem. Pharmacol., 2004, 67, 2023-2030.

[53] Ying, S.W.; Rusak, B.; Mocaer, B.Chronic exposure to melatonin receptors agonist does not alter their effects on supra chiasmatic nucleus neurons.SCN. Eur. J. Pharmacol., 1998, 342, 29-37.

54] Weaver, D.R.; Reppert, S.M. The Mel1 a receptor gene is expressed in human suprachiasmatic nucleus. Neuroreport, 1996, 109-112.

[55] Greenblatt, D.J.; Harmatz, J.S.; Karim, A. Age and gender effects on the pharmacokinetics and pharmacodynamics of ramelteon, a hypnotic agent acting via melatonin receptors MT1 and MT2. J. Clin. Pharmacol., 2007, 47, 485-496.

[56] Stevenson, S.; Bryson, S.; Amayke, D.; Hibberd, M. Study to investigate the absolute bioavailability of a single oral dose of ramelteon (TAK-375) in healthy male subjects. Clin. Pharmacol. Ther., 2004, 75, 22.

[57] Wu, Y.H.; Zhou, J.N.; Balesar, R.; Unmehopa, U.; Bao, A.; Jockers, R.; Van Heerikhuize, J.; Swaab, D.F. Distribution of MT1 melatonin receptor immunoreactivity in the human hypothalamus and pituitary gland: colocalization of MT1 with vasopressin, oxytocin, and corticotropin-releasing hormone. J. Comp. Neurol., 2006, 499, 897-910.

[58] Savaskan, E.; Olivieri, G.; Meier, F.; Brydon, L.; Jockers, R.; Ravid, R.; Wirz-Justice, A.; Müller-Spahn, F. Increased melatonin 1a-receptor immunoreactivity in the hippocampus of Alzheimer's disease patients. J. Pineal Res., 2002, 32, 59-62.

[59] Savaskan, E.; Ayoub, M.A.; Ravid, R.; Angeloni, D.; Fraschini, F.; Meier, F.; Eckert, A.; Müller-Spahn, F.; Jockers, R. Reduced hippocampal MT2 melatonin receptor expression in Alzheimer's disease. J. Pineal Res., 2005, 38, 10-16.

[60] Brunner, P.; Sozer-Topcular, N.; Jockers, Ravid, R.R.; Angeloni, D.; Fraschini, F.; Eckert, A.; Müller-Spahn, F.; Savaskan, E. Pineal and cortical melatonin receptors MT1 and MT2 are decreased in Alzheimer's disease. Eur. J. Histochem., 2006, 50, 311-316.

[61] Savaskan, E.; Jockers, R.; Ayoub, M.; Angeloni, D.; Fraschini, F.; Flammer, J.; Eckert, A.; Müller-Spahn, F.; Meyer, P. The MT2 melatonin receptor subtype is present in human retina and decreases in Alzheimer's disease. Curr. Alzheimer Res., 2007, 4, 47-51.

[62] Saper, C.B.; Lu, J.; Chou, T.C.; Gooley, J. The hypothalamic integrator for circadian rhythms. Trends Neurosci., 2005, 28, 152157.

[63] Kalsbeek, A.; Perreau-Lenz, S.; Buijs, R.M. A network of (autonomic) clock outputs. Chronobiol. Int., 2006, 23, 521-535.

[64] Reghunandanan, V.; Reghunandanan, R. Neurotransmitters of the suprachiasmatic nuclei. J. Circadian Rhythms, 2006, 4, 2.

[65] Pandi-Perumal, S.R.; Srinivasan, V.; Spence, D.W.; Moscovitch, A.; Hardeland, R.; Brown, G.M.; Cardinali, D.P. Ramelteon: a review of its therapeutic potential in sleep disorders. Adv. Ther., 2009, 26, 613-626.

[66] Srinivasan, V.; Pandi-Perumal, S.R.; Trahkt, I.; Spence, D.W.; Poeggeler, B.; Hardeland, R.; Cardinali, D.P. Melatonin and melatonergic drugs on sleep: possible mechanisms of action. Int. J. Neurosci., 2009, 119, 821-846.
[67] Roth, T.; Stubbs, C.; Walsh, J.K. Ramelteon (TAK-375), a selective MT1/MT2-receptor agonist, reduces latency to persistent sleep in a model of transient insomnia related to a novel sleep environment. Sleep, 2005, 28, 303-307.

[68] Roth, T.; Seiden, D.; Sainati, S.; Wang-Weigand, S.; Zhang, J.; Zee, P. Effects of ramelteon on patient-reported sleep latency in older adults with chronic insomnia. Sleep Med., 2006, 7, 312-318.

[69] Erman, M.; Seiden, D.; Zammit, G.; Sainati, S.; Zhang, J. An efficacy, safety, and dose-response study of Ramelteon in patients with chronic primary insomnia. Sleep Med., 2006, 7, 17-24.

[70] Roth, T.; Seiden, D.; Wang-Weigand, S.; Zhang, J. A 2-night, 3period, crossover study of ramelteon's efficacy and safety in older adults with chronic insomnia. Curr. Med. Res. Opin., 2007, 23, 1005-1014.

[71] Zammit, G.; Erman, M.; Wang-Weigand, S.; Sainati, S.; Zhang, J.; Roth, T. Evaluation of the efficacy and safety of ramelteon in subjects with chronic insomnia. J. Clin. Sleep Med., 2007, 3, 495504.

[72] Mini, L.; Wang-Weigand, S.; Zhang, J. Ramelteon 8 mg/d versus placebo in patients with chronic insomnia: post hoc analysis of a 5week trial using $50 \%$ or greater reduction in latency to persistent sleep as a measure of treatment effect. Clin. Ther., 2008, 30, 13161323.

[73] Dobkin, R.D.; Menza, M.; Bienfait, K.L.; Allen, L.A.; Marin, H.; Gara, M.A. Ramelteon for the treatment of insomnia in menopausal women. Menopause Int., 2009, 15, 13-18.

[74] Mayer, G.; Wang-Weigand, S.; Roth-Schechter, B.; Lehmann, R.; Staner, C.; Partinen, M. Efficacy and safety of 6-month nightly ramelteon administration in adults with chronic primary insomnia. Sleep, 2009, 32, 351-360.

[75] Uchimura, N.; Ogawa, A.; Hamamura, M.; Hashimoto, T.; Nagata, H.; Uchiyama, M. Efficacy and safety of ramelteon in Japanese adults with chronic insomnia: a randomized, double-blind, placebocontrolled study. Expert Rev. Neurotherapeutics, 2011, 11, 215224.

[76] Uchiyama, M.; Hamamuram, M.; Kuwano, T.; Nagata, H.; Hashimoto, T.; Ogawa, A.; Uchimura, N. Long-term safety and efficacy of ramelteon in Japanese patients with chronic insomnia. Sleep Med., 2011, 12, 127-133.

[77] Pandi-Perumal, S.R.; Srinivasan, V.; Poeggeler, B.; Hardeland, R.; Cardinali, D.P. Drug Insight: the use of melatonergic agonists for the treatment of insomnia-focus on ramelteon. Nat. Clin. Pract. Neuro., 2007, 3, 221-228.

[78] Richardson, G.S.; Zee, P.C.; Wang-Weigand, S.; Rodriguez, L.; Peng, X. Circadian phase-shifting effects of repeated ramelteon administration in healthy adults. J. Clin. Sleep Med., 2008, 4, 456461.

[79] McElroy, S.L.; Winstanley, E.L.; Martens, B.; Patel, N.C.; Mori, N.; Moeller, D.; McCoy, J.; Keck, P.E., Jr. A randomized, placebocontrolled study of adjunctive ramelteon in ambulatory bipolar I disorder with manic symptoms and sleep disturbance. Int. Clin. Psychopharm., 2011, 26, 48-53.

[80] Arendt, J.; Marks, V.Physiological changes underlying Jet lag. BMJCX, 1982, 284, 144-146.

[81] Takahashi, T.; Sasaki, M.; Itoh, H.; Yamadera, W.; Ozone, M.; Obuchi, K.; Hayashida, K.; Matsunaga, N.; Sano, H. Melatonin alleviates jet lag symptoms caused by $11 \mathrm{~h}$ eastward flight. Psychiatry Clin. Neurosci., 2002, 56, 301-302.

[82] Beaumont, M.; Batéjat, D.; Piérard, C.; Van Beers, P.; Denis, J.B.; Coste, O.; Doireau, P.; Chauffard, F.; French, J.; Lagarde, D. Caffeine or melatonin effects on sleep and sleepiness after rapid eastward transmeridian travel. J. Appl. Physiol., 2004, 96, 50-58.

[83] Zee, P.C.; Wang-Weigand, S.; Wright, K.P.Jr.; Peng, X.; Roth, T. Effects of ramelteon on insomnia symptoms induced by rapid, eastward travel. Sleep Med., 2010, 11, 525-533.

[84] Rajaratnam, S.M.W.; Polymeropoulos, M.H.; Fisher, D.M.; Roth, T.; Scott, C.; Birzinieks, G.; Klerman, E.B. Melatonin agonist Tasimelteon (VEC-162) for transient insomnia after sleep-time shift: Two randomized controlled multicenter trials. Lancet, 2009, 373, 482-491.

[85] Lankford, D.A. Tasimelteon for insomnia. Exprert Opin. Invest. Drugs, 2011, 20, 987-993.

[86] Mulchahey, J.J.; Goldwater, D.R.; Zemlan, F.P. A single blind placebo controlled cross escalation study of the safety, tolerability, pharmacokinetics and pharmacodynamics of the melatonin analog beta-methyl -6-chloro-melatonin. Life Sci., 2004, 75, 1843-1856. 
[87] Zelman, F.P.; Mulchahey, J.J.; Scharf, M.B.; Mayleban, D.W.; Rosenberg, R.; Lankford, A. The efficacy and safety of melatonin agonist beta-methyl-6-chloromeltonin in primary insomnia: a randomized place controlled crossover clinical trial. J. Clin. Psychiat., 2005, 66, 384-390.

[88] Cajochen, C.; Brunner, D.P.; Krauchi, K.; Graw, P.; Wirz-Justice, A. EEG and subjective sleepiness during extended wakefulness in seasonal affective disorder: circadian and homeostatic influences. Biol. Psychiatry, 2000, 47, 610-617.

[89] Armitage, R. Sleep and circadian rhythms in mood disorders. Acta Psychiatry Scand. Suppl., 2007, 104-115.

[90] Srinivasan, V.; Pandi-Perumal, S.R.; Trakht, I.; Spence, D.W.; Hardeland, R.; Poeggeler, B.; Cardinali, D.P. Pathophysiology of depression: role of sleep and the melatonergic system. Psychiatry Res., 2009, 165, 201-214.

[91] Reynolds, C.F.; Kupfer, D.J. In: Sleep Disorders, Diagnosis and Treatment; Williams, R.Z.; Karakam Moore, C.A., Ed.; John Wiley, New York, 1988, pp.147-164.

[92] Ohayon, M.M.; Roth, T. Place of chronic insomnia in the course of depressive and anxiety disorders. J. Psychiatr. Res., 2003, 37, 9-15.

[93] Srinivasan, V. Melatonin, biological rhythm disorders and phototherapy. Ind. J. Physiol. Pharmacol., 1997, 41, 309-328.

[94] Srinivasan, V.; Smits, M.; Spence, D.W.; Lowe, A.D.; Kayumov, L.; Pandi-Perumal, S.R.; Parry, B.; Cardinali, D.P. Melatonin in mood disorders. World J. Biol. Psychiatry, 2006, 7, 138-151.

[95] Kripke, D.F.; Mullaney, D.J.; Atkinson, M.; Wolf, S. Circadian rhythm disorders in manic-depressives. Biol. Psychiatry, 1978, 13(3), 335-351.

[96] Souetre, E; Salvati, E.; Belugou, J.L.; Pringuey, D.; Candito, M.; Krebs, B.; Ardisson, J.L.; Darcourt, G. Circadian rhythms in depression and recovery: evidence for blunted amplitude as the main chronobiological abnormality. Psychiatry Res., 1989, 28, 263278

[97] Hamet, P.; Tremblay, J. Genetics of sleep-wake cycle and its disorders. Metabolism, 2006, 55, S7-S12.

[98] Xu, Y.; Padiath, Q.S.; Shapiro, R.E.; Jones, C.R.; Wu, S.C.; Saigoh, N.; Saigoh, K.; Ptacek, I.J.; Fu, Y.H. Functional consequences of a CKI delta mutation causing familial advanced sleep phase syndrome. Nature, 2005, 434, 640-644.

[99] Reppert, S.M.; Weaver, D.R. Molecular analysis of mammalian circadian rhythms. Annu. Rev. Physiol., 2001, 63, 647-676.

[100] Ko, C.H.; Takahashi, J.S. Molecular components of the mammalian circadian clock. Hum. Mol. Genet., 2006, 2, R271-R277.

[101] McClung, C.A. Circadian genes, rhythms, and biology of mood disorders. Pharmacol. Ther., 2007, 114, 222-232.

[102] Archer, S.N.; Robilliard, D.L.; Skene, D.J.; Smits, M.; Williams, A.; Arendt, J.; von Schantz, M.A. Length polymorphism in the circadian clock gene Per3 is linked to delayed sleep phase syndrome and extreme diurnal preference. Sleep, 2003, 26, 413415.

[103] Johanson, C.; Willeit, M.; Smedh, C.; Ekholm, J.; Paunio, T.; Kieseppa, T.; Lichtermann, D.; Praschak-Rieder, N.; Neumeister, A.; Nilsson, L.G.; Kasper, S.; Peltonen, L.; Adolfsson, R.; Schalling, M.; Partonen, T. Circadian clock-related polymorphisms in seasonal affective disorder and their relevance to diurnal preference. Neuropsychopharmacology, 2003, 28, 734-739.

[104] Mishima, K.; Tozawa, T.; Satoh, K.; Saitoh, H.; Mishima, Y. The $3111 \mathrm{~T} / \mathrm{C}$ polymorphism of $\mathrm{h}$ clock is associated with evening preference and delayed sleep timing in a Japanese sample population. Am. J. Med. Gen. B. Neuropsychiatir. Genet., 2005, 133, 101-104.

[105] Vanselow, K.; Vanselow, J.T.; Westermark, P.O.; Reischl, S.; Maier, B.; Korte, T.; Herrman, A.; Herzel, H.; Schlosser, A.; Kramer, A. Differential effects of PER2 phosphorylation: molecular basis for the human familial advanced sleep phase syndrome (FASPS). Genes Dev., 2006, 20, 2660-2672.

[106] Kupfer, D.J. Depression and associated sleep disturbances; patient benefits with agomelatine. Eur. Neuropsychopharmacol., 2006 16(Suppl 5), S639-S643.

[107] Anderson, S.M. Selective serotonin reuptake inhibitors versus tricyclic antidepressants: a meta-analysis of efficacy and tolerability. J. Affect. Disord., 2000, 58, 19-36

[108] Yous, S.; Andrieux, J.; Howell, H.E.; Morgan, P.J.; Renard, P.; Pfeiffer, B.; Lesieur, D.; Guardiola-Lemaitre, B. Novel naphthalenic ligands with high affinity for the melatonin receptor. J. Med. Chem., 1992, 35, 1484-1486.

[109] Millan, M.J.; Gobert, A.; Lejeune, F.; Dekeyne, A.; NewmanTancredi, A.; Pasteau, V.; Rivet, J.M.; Cussac, D. The nove melatonin agonist agomelatine (S20098) is an antagonist at 5hydroxytryptamine $2 \mathrm{c}$ receptors, blockade of which enhances the activity of frontocortical dopaminergic and adrenergic pathways. $J$. Pharmacol. Exp. Ther., 2003, 306, 954-964.

[110] Srinivasan, V; Brzezinski, A.; Spence, D.W.; Pandi-Perumal, S.R.; Hardeland, R.; Brown, G.M.; Cardinali, D.P. Sleep, mood disorders and antidepressant agomelatine offers a new strategy for treatment. Psychiatrica Fennica, 2010, 41, 168-186.

[111] Srinivasan, V.; Zakaria, R.; Othman, Z.; Lauterbach, E.D.; AcunaCastroviejo, A. Agomelatine in depressive disorders, its novel mechanism of actions. J. Neuropsychiatry Clin. Neuro. Sci., 2012 in press.

[112] Guilleminault, C. Efficacy of agomelatine versus venlafxine on subjective sleep of patients with major depressive disorder. Eur. Neuropsychopharmacology, 2005, 15 (Suppl. 3), S419.

[113] Quera, Salva, M.A.; Vanierm B.; Laredo, J.; Hartley, S.; Chapotot, F.; Moulin, C.; Lofaso, F.; Guilleminault, C.Major disorder, sleep, EEG and agomelatine: an open label study. Int. J. Neuropsychopharmacol., 2007, 10, 691-696.

[114] Quera, Salva, M.A.; Lemoine, P.; Guilleminault, C. Impact of the novel antidepressant on disturbed sleep-wake cycles in depressed patients. Hum. Psychopharmacol., 2010, 25, 222-229.

[115] Lopes, M.C.; Quera-Salva, M.C.; Guilleminault C. Cycling alternating patterns within major depressive disorder: baseline results and changeovertime with a new antidepressant. Sleep Med., 2005, 6(Suppl. 2), 87-88.

[116] Ruhe, H.G.; Mason, N.S.; Schene, A.H. Mood is indirectly related to serotonin, norepinephrine, and dopamine levels in humans. A meta analysis of monoamine depletion studies. Mol. Psychiatry, 2007, 12, 331-359.

[117] Wang-Weigand, S.; McCuea, M.; Ogrinca, F.; Mini, L. Effects of ramelteon $8 \mathrm{mg}$ on objective sleep latency in adults with chronic insomnia on nights 1 and 2: pooled analysis. Curr. Med. Res. Opin., 2009, 25(5), 1209-1213.

[118] Zammit, G.; Schwartz, H.; Roth, T.; Wang-Weigand, S. The effects of ramelteon in a first-night model of transient insomnia. Sleep Med., 2009, 10(1), 55-59. 